\title{
A FRAMEWORK FOR COLLABORATIVE AND ACTIVE LEARNING FOR ENHANCING STUDENT ENGAGEMENT
}

\author{
Muhammad Mustafa ${ }^{1}$, Vikas Rao Naidu ${ }^{2 *}$, Qais Ali Mohammed ${ }^{3}$, \\ Karan Ajit Jesrani ${ }^{4}$, Raza Hasan ${ }^{5}$, Ghaniya Al Hadrami ${ }^{6}$ \\ ${ }^{1}$ Mr., Middle East College, OMAN,11s7131@mec.edu.om \\ ${ }^{2}$ Mr., Middle East College, OMAN, vikas@mec.edu.om \\ ${ }^{3}$ Mr., Middle East College, OMAN, 13f10559@mec.edu.om \\ ${ }^{4}$ Mr., Middle East College, OMAN, kjesrani@mec.edu.om \\ ${ }^{5} \mathrm{Mr}$., Middle East College, OMAN, raza@mec.edu.om \\ ${ }^{6}$ Ms., Middle East College, OMAN, ghaniya@mec.edu.om \\ ${ }^{*}$ Corresponding Author
}

\begin{abstract}
The developing technology has influenced and enhanced the life around us, so the use of the digital resources must not be hindered to serve the educational, teaching and learning sectors, in the modern times more emphasis is laid on the ways of education, relating to the teaching and learning techniques or methods used in the institutions, colleges or universities, on how the learning and teaching methods be enhanced so the students learn more comfortably and in a better way suiting their capacity or learning demands. As well, it will help the teachers to convey the topic concepts in a more relevant way to the students, helping them understand better and learn in an effective way.

For this concept of enhancement in teaching and learning, many steps are been taken around the globe, many methods are been used like for instance the flip teaching technique, where the students are required to go through the learning material provided by the teacher to further explore the concepts, which are explained during the classes. Other methods include research-based learning and many more, but in the current course of time, individual traits of students when it comes to learning is often neglected, due to which the students find it difficult to understand and learn better, due to each student being unique and having various personalities and mindsets. A framework must be devised to enhance the earning ability of students based on their personalities. Modern technological tools must be used to support in the direction of teaching based on an individual's personalities and mindsets. Various groups can be formed of the students who fall into a certain category, teaching methods must be devised and quality checks must be ensured. Their learning outcomes must be measured based on their teaching methods implemented by the teachers.
\end{abstract}

Keywords: Education Technology, E-learning, Collaborative Learning environment, Innovation in Teaching and Learning, Smart Education

\section{INTRODUCTION}

The latest model of teaching and learning in almost every higher education institution has a part of a collaborative learning space. While designing any assessment with the group component, teachers need to make sure that the exercise goes smoothly during and after the session. Although many existing models are available, still there are chances when it becomes difficult for a teacher to assess individual contribution in the group assessment or any other exercise done in a collaborative learning environment. 
IJAEDU- International E-Journal of Advances in Education, Vol. V, Issue 13, April, 2019

In this paper, authors have suggested a detailed framework with title "Butterfly framework for collaborative learning space" and explained various implications of its usage in real time.

\section{RELATED STUDY}

There are many types of assessment in education and their brief examples are included in this video like formative assessment which is for quick check of understanding examples are brainstorming and thumbs up/down, summative assessment for long term goals e.g.: midterms, unit tests, projects etc., Diagnostic assessment pre-course test to get prior knowledge of students, formal assessment are strict and examples are standardized test, informal assessment, behavioral assessment are common in special students classes, rating scales where scores are based on rating, emotional assessment target on the emotions of the students and e.g. is a checklist and questionnaires, screening assessment is based on RTI response to intervention which is gaining popularity, Authentic assessment require settings which are authentic speech, report, interview etc., Performance-based assessment based on the ability to achieve academic tasks . apart from this other sometimes students work in a group and may require individual expression so assessments for this scenario include IEPS is a common example, criterion referenced test aka carts, norm assessment compares students based on demographics. (Education, 2016)

This video review was helpful in noting the various assessment techniques and their example which are explained briefly and give an idea of what type of assessments are suitable in what context and for what kind of individuals, many of these assessment techniques can be enhanced or based on this simple techniques new framework can be implemented.

In this Ted talk video by Mr.Joe Ruhl, who has 37 years of experience in teaching he explains how it would be better to move from a teacher centered classroom to a student centered classroom. To be more of a guide on the side than a lecturer on stage, be a mentor not merely for teaching only and open opportunities to more. And focus more on choices, which gives opportunities for the students to express themselves more fearlessly, they should choices, and he emphasized on the concept of $5 \mathrm{cs}$, which are choices, collaboration, communication, critical thinking and creativity. He believes it we are made in learning this way having the 5 c's in it. We all love choices, and a student learning system should be developed which must be having these elements combined to encourage inspiration. He also emphasized that there are two types of techniques we require, which are relationship based teaching technique and the other is a relationship based, the latter is huge. (Ruhl, 2015)

We should be more responsive to the initiated ideas of the students and listen to their desired thoughts, to work as a guide on the side. Which will enable them to express the students' more effectively. Traditional standards of teaching are important but it must not hinder the creativity of students and limit their performances. Students must remember most, and must not struggle to just pass out a course work.

It was a very helpful speech by Mr.Joe Ruhl, which is to give more importance to the new innovative standard suiting as per the demands of the student majority, it must not be based on the normal standard procedures, which are not letting the students make the most out of their self-creativity. A teaching framework must be based on the mind-sets and phycology of students, which methods are the most comfortable with. And which framework suits them based, they must have choices, they must be able to explore their creativity, they must be able to think critically, which will help them to communicate and collaborate with confidence.

The teacher's responsibility is to identify the needs and problems of the student with the acquisition of knowledge. Tools are used to teach computer equipment for better understand the students, which enables the students to visualize the actual work inside the equipment for enhancing their cognitive skills (Kazmi, Hayat, Hasan, \& Dattana, 2017) (Siddiqui, Hasan, Mahmood, \& Khan, 2012) (Hasan \& Mahmood, 2012). Collecting footprints the student leaves for the measure of their academic progress, helping facilitators with the detailed student's data with instantaneous feedback (Hasan, Ali, \& Hayat, 2015). The study shows activity-based learning to increase student involvement and learning experience in which the teacher observed the impact of teaching and learning (Hayat, Hasan, Ali, \& Kaleem, 2017). The learning environment is designed to encourage best learning practices and involves students to the full (Bhatia \& Naidu, 2017) (Naidu, Singh, Hasan, \& Hadrami, 2017). Interactivity tools to increase understanding of basic concepts (Raweehi, Ansari, Udupi, \& Naidu, 2017) (Farsi, Udupi, \& Naidu, 2017), tools are used by teachers to enhance the learning process with different teaching and learning pedagogies (Naidu, Balushi, \& Bhatia, 2017) (Naidu, Singh, Harrasi, \& Balushi, 2017).

This framework comes under the domain of design thinking and is based on looking, listening and learning, which is the first phase. To reach the goal which is awareness, and they will have questions to ask, so the second phase is questioning, to clear doubts and for more clarity of the concepts, it emphasis the students to 
take the research based approach, e.g. Analyze the data, brainstorm, read articles. The navigation is done based on learning. The next phase is of creating a prototype, which can be anything the student is involved in as per the specialization, highlight the successful part and the negative failing part, and then in the launch the product or project. (Spencer, 2016)

This process is important to study and know that design thinking is important when it comes to teaching and learning, it can convey the concept more relevantly and it can help the student enhance their cognitive ability. To encourage creativity deployment in what they are going to do. Research is very important, as it is an individual takes even if they are working in groups they have to use some skills to understand the concept, to play their part, this is, in the end, enhancing the students ability to learn and understand the concept and play a better role in groups, and when these students are assessed, they will be able to better present themselves with confidence and true achievement. This methodology of design thinking must be implemented for enhancing the education of the students and see better results in individual assessments and group assessments.

The toxic education system culture. Once we know the flaws, we can find a solution, ignorance must be ignored. If we need innovations and improvements in society, may that be any field or domain of interest. Let's come down to the education system and education of students, the norms that describe the education system. In this video, Mr. Joshua Katz, a math teacher belonging to Orange County, it is highly research based talk and a powerful speech on the ignorance of the society, what should be improved and what is trying to improve, are two different things. The education system was labelled a failure because they hindered the development of cognitive abilities of students, the policies were not research based and surely didn't keep in mind the end user of the system, who are the teachers and the students. The students fear to conduct any challenging tasks but follow the normal routine of well-educated classes, the students must be taught the topic of interest and should be allowed to experience the field work to get an end idea of living on these future professions. (Katz, 2014)

A collaborate peer review of teachers must be exercised just like in any other professions, to review the students work and the state of mind and interests, to check the current framework of education used and what changes must be made to improve the system and encourage the innovation. Which can increase the individual ability of students rather than just achieving the grade to pass out. An education system based to enhance the student ability is important rather than implementing a system which is not based on the end users interests. (Katz, 2014)

So why student's ability should be based on a biased understanding of the education system. This ted talk speech is highly motivational to know the root causes of the failed education system, and how it can be improved, why it is highly required to devise a framework which can enhance productivity and real education based on the true achievement of students. It is more important to get the students educated than getting them enrolled.

\section{ANALYSIS}

A questionnaire is a very important and effective tool for data collection and feedback collection, the responses can easily be converted into graphs and charts for analysis. Google forms help to develop questionnaires, share and then later also demonstrates graph outputs.

Before planning the design of a proposed system, a survey was conducted among 53 students from various higher education institutions across the country (Oman) to assess their point of view on this proposed implementation.

53 responses were collected and then evaluated which proved the following results:-

As shown in Fig 3.1, over 63.5\% responses were no, and $32.7 \%$ yes, and the remaining sometimes yes (1\%) and to an extent (1\%). It can be concluded from the answers that the current mode of teaching more improvements, which should be relevant to all the students. 
Is the normal mode of teaching technique used in college relevant to your needs?

52 responses

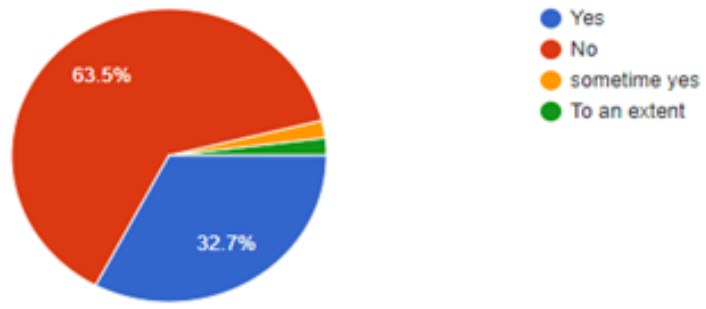

Fig 3.1 - Question 1

Fig. 3.2 shows that $69.2 \%$ said yes and $30.8 \%$ said no, the majority said they were aware of the various teaching methods. While the minority in them stated they are unaware of various techniques and methods.

\section{Are You aware of various teaching techniques and methods?}

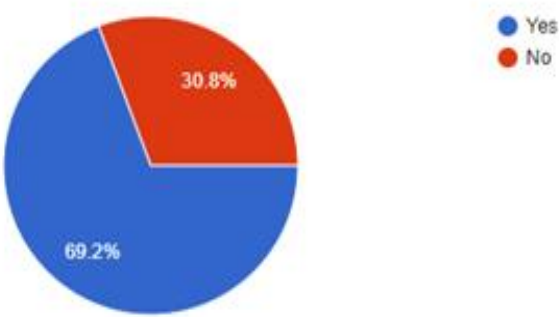

Fig 3.2 - Question 2

Fig 3.3 shows various teaching methods awareness rates.

Out of the ones who said they are aware of the teaching methods, the highest rate is of flip teaching $(77.8 \%)$, which is the current technique used in the college, and the least rate is of role plays (13\%).

\section{Which of the following teaching methods are you aware of?}

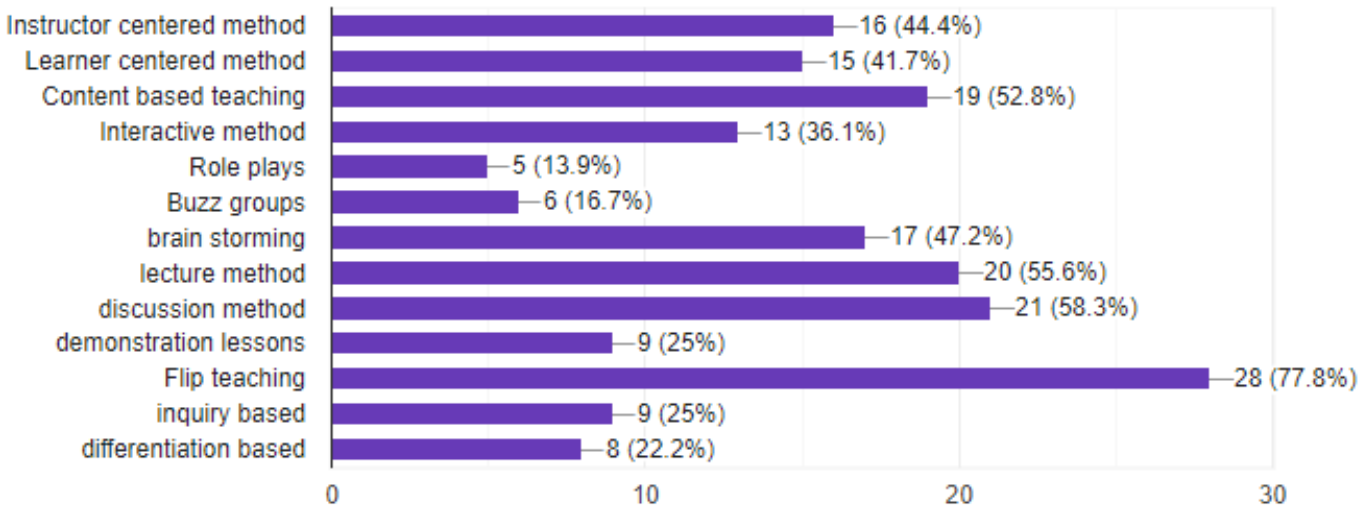

Fig. 3.3 - Question 3

Responses were seen in Fig. 3.4 shows the importance of assessment for encouraging true individual contribution of students: 
Impact of individual contribution assessment on learning

Do you think Individual contribution assessment is necessary to know the true achievement of the student?

52 responses

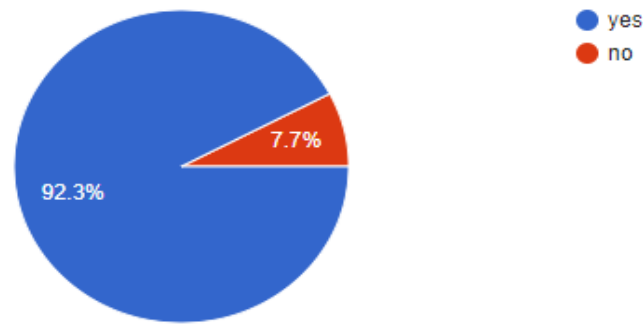

Fig. 3.4 - Question 4

Fig. 3.4 shows that $92.3 \%$ agreed "yes" and $7.7 \%$ said "no", it can be seen that the majority have agreed on the importance of individual contribution assessment, and the minority did not refer to it. Which is an important notification for the individual assessment framework.

Fig. 3.5 shows that $90.4 \%$ agreed while the other $9.6 \%$ disagreed, the majority here too have agreed upon individual assessment is being a positive and effective step.

\section{Do you think that modern tools can be used for assessing individual contribution of students?}

52 responses

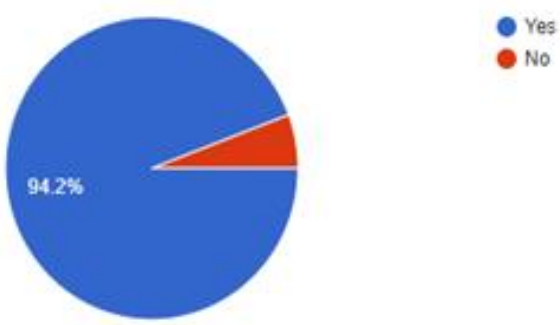

Fig. 3.5 - Question 5

Fig. 3.6 shows that $94.2 \%$ agreed on it and the remaining $5.8 \%$ disagreed. Which concludes that modern tools can be used to create an assessment system or the system developed must have a contribution assessment framework implemented to enhance the eLearning and the education of the students. By improving their performances. 


\section{Do You agree that individual contribution assessment can enhance or have a positive effect learning outcomes?}

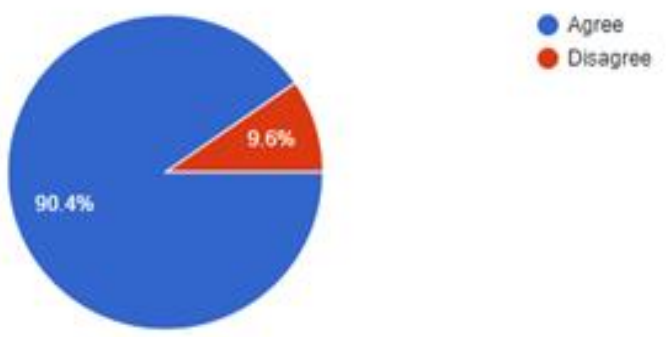

Fig. 3.6 - Question 6

As seen in Fig 3.7, 78.8\% said yes and the other $21.2 \%$ said no, majority have agreed on the fact that individual efforts are often neglected during group works, and hard work done by the students are not known, due to grouped presentation, and there are many issues faced when distributing the tasks, and getting fruitful results by all the members, in fact some members don't work or contribute much at all, and in the end all the members share the credit of effort of one or two hard working students. Multiple responses can be viewed below as follows.

\section{Are there issues faced by you working in a team for group works}
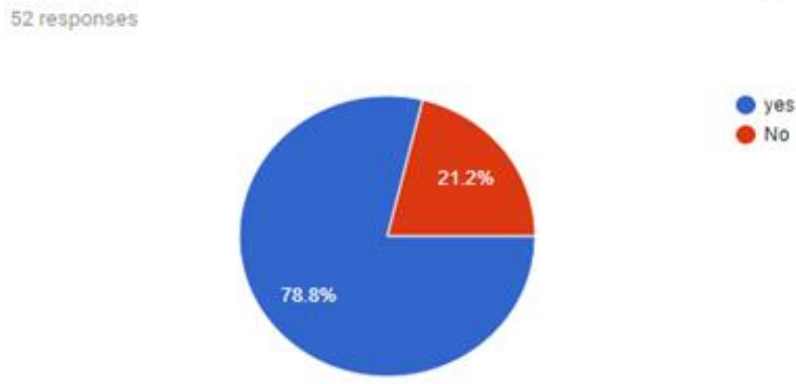

Fig. 3.7 - Question 7

The conclusion, from the questionnaire feedback analysis it can be studied that the students require a more suitable framework for learning individual assessment. A framework that is more relevant to the mindsets of the students and their personalities. It should be more student centered and should not only allow to get good grades but improve concept learning and understanding. And the enhanced group works assessments should confirm the true contribution of students, based on the clarity and understanding of the job done by each of them, so that all get a fair share of their efforts, which will increase the confidence of students to express themselves.

\section{PROPOSED FRAMEWORK}

Butterfly framework for enhancing learning and teaching:- As the name suggests the concept diagram seems like a butterfly. That is why this concept named after the butterfly. Centered processes flow from top to bottom, and the processes or actions which are represented on the right and left sides with curved arrows linking the blocks or actions seem like wings, identical wings. This framework is devised to view parallel workflow processes done by the two major actors: the students and teachers, per module. The framework follows the Top to bottom approach. The rectangle represents the common process or the steps in which both the actors are involved in. At the beginning of a semester or course work, the actions of students and teachers go hand in, like the teacher comes to teach, the students attend the class. A lecture is given and a concept is understood etc.

The framework, as shown in Fig 4.1, is based on the structure of sessions, and the logical activities are represented with respective links on the sides. The series of activities involved as per the duty requirements of the actors are assembled.

\section{Corresponding to the above framework description}

The top to bottom structure contains modules which are related to the session, starting from course work 
resumes, now in the course work the first module is class work procedure, in this module the series of activities are linked which are executed by the students and the teachers, meaning what each will do during this module, what are the tasks they need to perform in class work procedures.

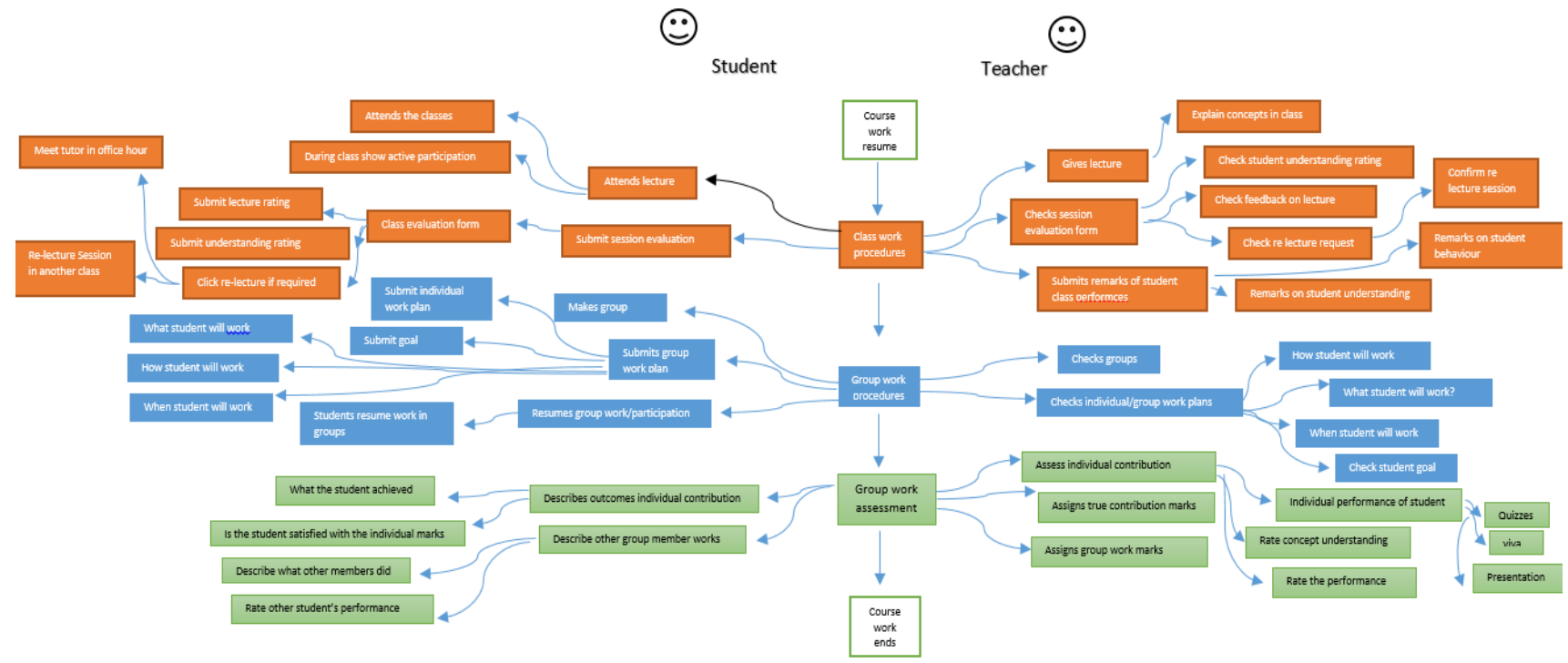

Fig 4.1: Butterfly Framework for Collaborative Learning Space

\subsection{Step1 Class work procedure}

Student: In this module the Students attend the class and attend the lecture, they grasp knowledge, and after the class they fill the class evaluation form, in which they describe their understanding of the concepts taught in the class and whether or not they understood or not, they rate the understanding of the concepts explained, if they require a re-session or want to know the clarify their concepts they can refer to the lecturer by booking an office hour or if the majority of the students didn't understand the lecture can be given again in another session or an extra class. This requests or actions can be confirmed by the tutor.

Teachers: in this module the Teachers gives lecture during the class and then assess the class evaluation form which are submitted by students after class, and which shows the ratings and comments given by the students on the understanding of the lecture and the concepts explained, If they require a re-class or want to understand or clarify the concepts, the teacher can confirm a meeting hour, office hour or a re-lecture in the next session if the majority of the students require it. The teacher also evaluates the student's performances and activeness in the class and fills the remarks on the students, how well the students understood by checking the ratings by the students and the teacher also gives remarks on the student's behavior during the class.

Note: this is a repetitive step and it will repeat weekly in every class till the course plan executes.

And more activities can be added as per the requirements.

\subsection{Group work procedure}

Students: In this module the students during this session makes group for the group assignment task, and then each one send the group work plan, which includes group members to decide what each member will do, each student submit the individual goals that they expect to achieve by individual participation in the group work, and each member states what they will do in this project, how they will complete it, and what is the duration they will complete there stated tasks. After describing all the details the student then resumes the individual works while also participating in the group.

Teachers: the teacher checks the group, how many members are in them for the group related tasks, and then assess the individual plans of the group members within different groups, what each member will do, and how he/she will do it, and in what duration are they expecting to achieve the tasks done. What are the individual goals that they expect to fulfil.

\subsection{Group work assessment module}

Students: In this section, the group members describe what they have achieved individually by checking the marks, and also describing what knowledge they have gained. Are they satisfied with the individual marks, 
and also describe what other group members have done which includes what the other members did (which part of the assignment and what was their contribution) and also describe how well they did it(They also rate and comment on the performance of other group members and their contribution.)

The teachers: the teacher here assesses the individual contribution of the students which is based on the understanding (by taking personal quizzes, viva, and presentation via an online tool) by the concepts and the performance rating given by the tutor and the other members in the class. And then individual rating and marks to the members of the groups and also gives the marks of the total group assignment work.

And these modules are reusable, and can be used during classes, the group works, and group work assessments any time till the course work completes.

\section{IMPLEMENTATION}

The proposed framework could be implemented in various ways, based on the level and content of the topic to be covered in the session. Since it is meant for a collaborative learning environment, the implementation also depends on the size of the cohort. One of the suggested implementation methods is provided in the following figure.

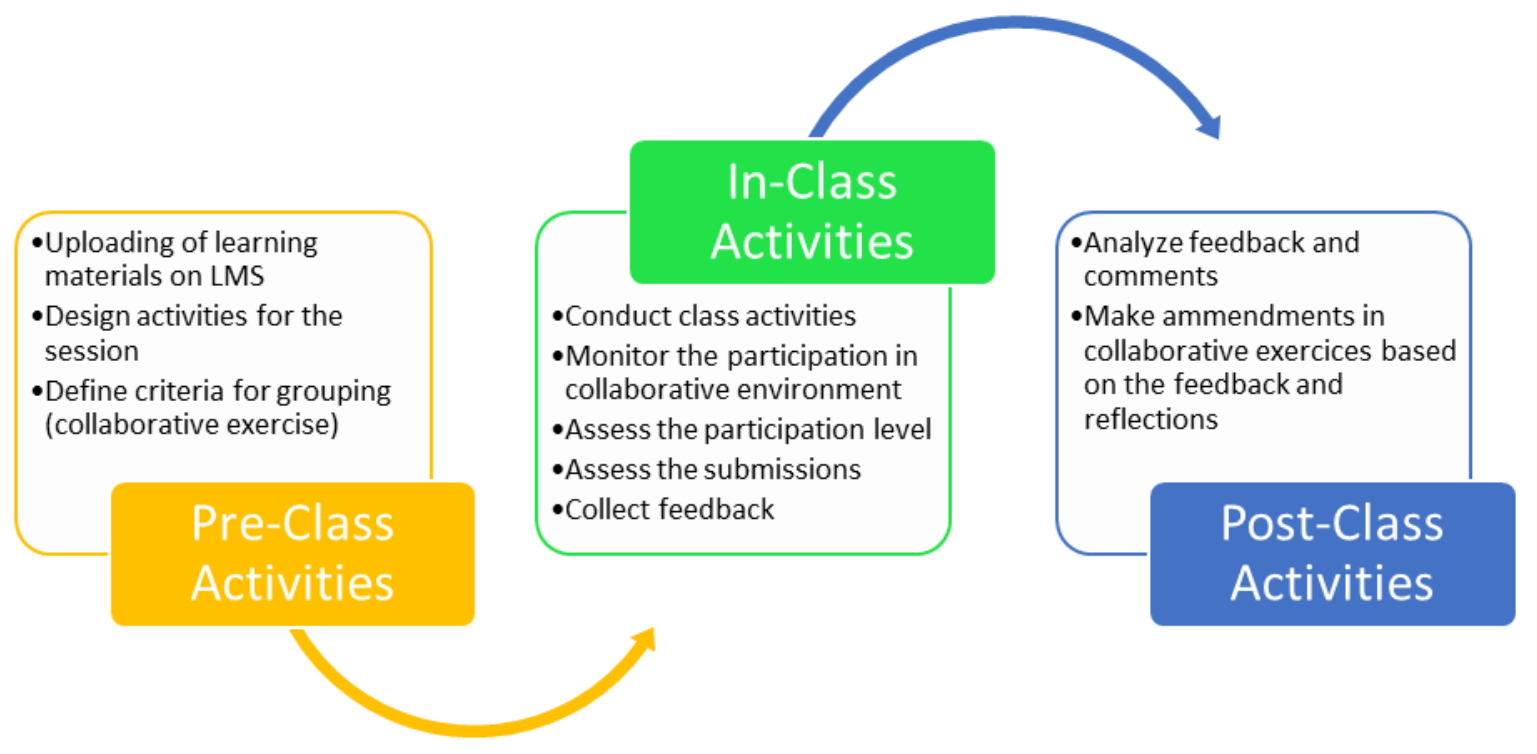

Fig.5.1 Proposed Implementation

\subsection{Pre-Class Activities}

At this stage, the faculty needs to upload the learning materials on the Learning Management System (LMS) in prior, which could be accessed by the students before coming to the class. These materials could be in any form such as multimedia based audio-visual materials, or e-book or any online resource. Then the activities need to be designed for the session, which should be based on the size of the cohort. For instance, if the cohort size is very less, then a large number of groups cannot be formed during the conduct of these exercises. Moreover, criteria should be clearly defined based on which these grouping needs to be done. For this, one brainstorming exercise could be conducted at the beginning of the session and based on the student's participation, grouping could be done. More active students could be grouped with the students who are unable to participate actively due to some constraints.

\subsection{In-Class Activities}

In this second stage of implementation, class activities are conducted based on the plan prepared in the previous stage. Monitoring of these activities is very important, especially in collaborative exercises. During these activities, the participation level should be assessed by the faculty. Once students complete their tasks, they need to submit their outcomes in the required format, such as, report or presentation which is assessed in order to check the results. Finally, feedback is collected from every group member. 


\subsection{Post-Class Activities}

At this stage, the feedback and reflections are analysed in order to make necessary amendments in the activities to be given to the next batch. The effectiveness of this implementation could be measured by means of these feedback analysis (quantitative/qualitative).

\section{BENEFITS OF PROPOSED FRAMEWORK}

Some benefits of the proposed framework are identified as follows:

- It is reusable, as it is a framework with a loop structure.

- It gives the opportunity to add or remove the modules or processes that the teachers and students will perform during the classes, for group works, group work assessments, exams, individual assignments etc.

- It is not complicated.

- Self-prepared processes can be introduced and involved in any models, it almost seems like a selfpaced model.

- Ease of making and viewing activities, generalization and linking the related ones.

- Ease of understanding.

- The logical flow of process involved

- Structured based.

- Can be prepared for any session or modules, implementation as per user requirements.

- Ease of describing actor's tasks or activities as per the modules.

\section{CONCLUSION}

It is really important to identify an appropriate methodology before devising any new teaching and learning strategy for an institution. It must make sure that all the learning outcomes are being covered and without complete test with favourable results, it should not be implemented in real time.

The proposed framework could be really supportive especially for the teachers who are planning to conduct group based activities and assessments, in which they need to measure individual contribution. But the faculty must identify the appropriate module and session and check the learning outcomes to make sure that this model suits their requirement.

Further customization can be done based on the requirements, identified from feedback and results, or a group project and group assignment in order to enhance the mechanism of assessments. This feedback can also be integrated to capture with the help of latest technologies like loT and ontology to get the students behaviour and data (Mahmood et al., 2019) (Sarker et al., 2019). The capturing of information can be done using cloud based or with the use of multimedia where understanding is more in the modern era of Education 4.0. Virtual learning can also be implemented in future to get the feedback on the students learning and adaptation of the new technologies (Al Mahdi, Rao Naidu \& Kurian, 2019) (Hasan et al., 2019) (GebreYohannes, Bhatti, \& Hasan, 2016). These can help faculty to make and do the assessments in a better way. Using cloud technologies for innovation education where data can be stored for knowledge management such as social media (Ali \& Naidu, 2019) and this data can be analysis for BigData and visualization purposes or for early detection for student's performance in the module (Bhat, Naidu \& Singh, 2018) (Naidu, Bhat \& Singh, 2019) (Hasan et al., 2019) (Hasan, Palaniappan, Raziff, Mahmood \& Sarker, 2018).

\section{REFERENCE LIST}

Al Mahdi, Z., Rao Naidu, V., \& Kurian, P. (2019). Analyzing the Role of Human Computer Interaction Principles for E-Learning Solution Design. Smart Technologies and Innovation for a Sustainable Future, 41-44. doi: 10.1007/978-3-030-01659-3_6

Ali, Q., \& Naidu, V. (2019). Using Social Media as a Collaborative Tool for Enhanced Learning in Higher 
IJAEDU- International E-Journal of Advances in Education, Vol. V, Issue 13, April, 2019

Education. $6^{\text {th }}$ Academic International Conference on Multi-Disciplinary Studies and Humanities (pp. 85-92). Oxford: Oxford Conference Series.

Bhat, A., Naidu, V., \& Singh, B. (2018). Multimedia Cloud for Higher Education Establishments: A Reflection. Advances in Intelligent Systems And Computing, 691-698. doi: 10.1007/978-981-13-2285-3_81

Bhatia, S., \& Naidu, V. R. (2017). Flipped Teaching in Mathematics. International Conference on Education and New Learning Technologies. Barcelona, Spain: EDULEARN17.

Education, T. i. (2016, Dec 18). Assessment in Education: Top 14 Examples. Retrieved from Youtube: https://www.youtube.com/watch?v=zTkQjH-_97c

Farsi, M. H., Udupi, P. K., \& Naidu, V. R. (2017). Interactive Education Application Development Using FOSS for Government School in Oman. Free and Open Source Software Conference, (pp. 71-75). Muscat, Oman.

GebreYohannes, H. M., Bhatti, A. H., \& Hasan, R. (2016). Impact of multimedia in Teaching Mathematics. International Journal of Mathematics Trends and Technology (IJMTT), 39(1).

Hasan, R, Palaniappan, S, Mahmood, S, Shah, B, Abbas, A, Sarker, K. (2019). Enhancing the Teaching and Learning Process Using Video Streaming Servers and Forecasting Techniques. Sustainability 11(7): 2049.

Hasan, R., Ghufran, M., Javed, S., Hammad-ul-Haq, Azeem, A., \& Jamil, D. (2019). SMART Virtual Dental Learning Environment. $20194^{\text {th }}$ MEC International Conference on Big Data And Smart City (ICBDSC). doi: 10.1109/icbdsc.2019.8645584

Hasan, R., Palaniappan, S., Raziff, A., Mahmood, S., \& Sarker, K. (2018). Student Academic Performance Prediction by using Decision Tree Algorithm. $20184^{\text {th }}$ International Conference On Computer And Information Sciences (ICCOINS). doi: 10.1109/iccoins.2018.8510600

Hasan, R., \& Mahmood, S. (2012). Survey and evaluation of simulators suitable for teaching for computer architecture and organization Supporting undergraduate students at Sir Syed University of Engineering \& Technology. Proceedings of 2012 UKACC International Conference on Control (pp. 1043-1045). Cardiff, UK: IEEE.

Hasan, R., Ali, S. I., \& Hayat, M. (2015). Enhancing student's learning experience at middle east college by using blended learning. 2015 Science and Information Conference (SAI) (pp. 797-800). London, UK: IEEE.

Hayat, M., Hasan, R., Ali, S. I., \& Kaleem, M. (2017). Active learning and student engagement using Activity Based Learning. 2017 International Conference on Infocom Technologies and Unmanned Systems (Trends and Future Directions) (ICTUS). Dubai, United Arab Emirates: IEEE.

Katz, J. (2014, May 2). Toxic culture of education: Joshua Katz at TEDxUniversityofAkron. Retrieved from YouTube: https://www.youtube.com/watch?v=BnC6IABJXOI

Kazmi, S. I., Hayat, M. S., Hasan, R., \& Dattana, V. (2017, October). Network simulation tool enhances learning and understanding of computer network protocol concepts in middle east college. Airo International Research Journal, 13.

Mahmood, S., Palaniappan, S., Hasan, R., Sarker, K., Abass, A., \& Rajegowda, P. (2019). Raspberry PI and role of IoT in Education. $20194^{\text {th }}$ MEC International Conference on Big Data And Smart City (ICBDSC). doi: 10.1109/icbdsc.2019.8645598

Naidu, V., Bhat, A., \& Singh, B. (2019). Cloud Concept for Implementing Multimedia Based Learning in Higher Education. Smart Technologies and Innovation for a Sustainable Future, 81-84. doi: 10.1007/978-3-030-01659-3_11

Naidu, V. R., Balushi, H. A., \& Bhatia, S. (2017). Effectiveness Of Free \& Open Source Tools To Enhance Game Based Learning Experience In School Education. International Conference on Education and New Learning Technologies. Barcelona, Spain: EDULEARN.

Naidu, V. R., Singh, B., Harrasi, R. A., \& Balushi, H. A. (2017). Technology Enhanced Learning Assisted By Free And Open Source Software. 4th International Conference on Education, Social Sciences and Humanities. Dubai, UAE: SOCIOINT.

Naidu, V. R., Singh, B., Hasan, R., \& Hadrami, G. A. (2017). Learning Analytics for Smart Classrooms in Higher Education. International E-Journal of Advances in Education, 3(8), 440-446. 
Raweehi, M. G., Ansari, W. A., Udupi, P. K., \& Naidu, V. R. (2017). Interactive E-Book Development using FOSS. Free and Open Source Software Conference, (pp. 67-70). Muscat, Oman.

Ruhl, J. (2015, May 27). Teaching Methods for Inspiring the Students of the Future / Joe Ruhl / TEDxLafayette. Retrieved from Youtube: https://www.youtube.com/watch?v=UCFg9bcW7Bk

Sarker, K., Bin Deraman, A., Hasan, R., Mahmood, S., Abbas, A., \& Sohail, M. (2019). Kids' Smart Campus Ontology to Retrieve Interest. $20194^{\text {th }}$ MEC International Conference on Big Data And Smart City (ICBDSC). doi: 10.1109/icbdsc.2019.8645585

Siddiqui, O. A., Hasan, R., Mahmood, S., \& Khan, A. R. (2012). Simulators as a Teaching Aid for Computer Architecture and Organization. 2012 4th International Conference on Intelligent Human-Machine Systems and Cybernetics (pp. 110-113). Nanchang, Jiangxi, China: IEEE.

Spencer, J. (2016, Feb 14). The LAUNCH Cycle: A Design Thinking Framework for Education. Retrieved from YouTube: https://www.youtube.com/watch?v=LhQWrHQwYTk 